\title{
Starvation Ketoacidosis With Hypoglycemia in a Patient With Chronic Pancreatitis
}

\author{
Masakazu Kakurai ${ }^{1}$, Hiroshi Ito ${ }^{1}$, Nako Matsumoto ${ }^{2}$, Nobutake Shimojo ${ }^{1}$, Satoru Kawano ${ }^{1}$ \\ 1. Division of Hospital Medicine, University of Tsukuba Hospital, Tsukuba, Ibaraki, JPN 2. Department of \\ Endocrinology and Metabolism, University of Tsukuba Hospital, Tsukuba, Ibaraki, JPN
}

Corresponding author: Hiroshi Ito, itohirokan@yahoo.co.jp

\begin{abstract}
Chronic pancreatitis is a pancreatic inflammation that can result in endocrine pancreatic insufficiency. We present a case of starvation ketoacidosis in a 44-year-old Japanese man with chronic alcoholic pancreatitis. On admission, he exhibited hypoglycemia and severe acidosis. Intravenous glucose and vitamin B1 were administered in the emergency department, and nutritional management for presumed starvation ketoacidosis was begun. Because the patient did not have diabetes mellitus, his insulin secretion and insulin resistance were examined. A diagnosis of pancreatic diabetes caused by chronic pancreatitis was made based on decreased insulin secretion, normal insulin resistance, and negative anti-glutamic acid decarboxylase antibody. Intensive insulin therapy was initiated, and he was discharged 15 days after hospitalization. Although starvation rarely causes hypoglycemia and severe ketoacidosis, they can be induced by short-term fasting in patients with decreased pancreatic function.
\end{abstract}

Categories: Endocrinology/Diabetes/Metabolism, Emergency Medicine, Family/General Practice Keywords: starvation ketoacidosis, hypoglycemia, chronic pancreatitis

\section{Introduction}

In chronic pancreatitis, a multifactorial, fibroinflammatory syndrome, repeated episodes of pancreatic inflammation results in endocrine pancreatic insufficiency [1]. Decreased pancreatic hormones, including insulin, glucagon, and somatostatin, can deteriorate the control of serum glucose and ketone bodies [2]. Starvation ketosis is generally caused by fasting, eating disorders, or pregnancy [3]. It usually presents with mild hyperglycemia and rarely causes severe acidosis [4]. However, little is known about the presentation of starvation ketosis in patients with decreased pancreatic function.

Review began 01/05/2021 Review ended 01/15/2021 Published 01/17/2021

(c) Copyright 2021

Kakurai et al. This is an open access article distributed under the terms of the Creative Commons Attribution License CC-BY 4.0., which permits unrestricted use, distribution, and reproduction in any medium, provided the original author and source are credited.

\section{Case Presentation}

A 44-year-old Japanese man was admitted to the emergency department because of acute diarrhea, nausea, and mild abdominal pain. These symptoms were preceded by two days of inadequate oral intake due to adjustment disorder after changing his job. He had a medical history of alcoholic pancreatitis and pancreatic cyst for which he had undergone distal pancreatectomy two years earlier. His medication included pancrelipase, lansoprazole, and tramadol. Until two years earlier, he had been drinking $70 \mathrm{~g}$ of alcohol per day, but he denied any recent alcohol intake and illicit drug use. For confirmation, we heard from his wife about his behavior, who also denied alcohol and illicit drug consumption. On admission, his vital signs showed an axillary body temperature of $38.2^{\circ} \mathrm{C}$, a heart rate of 124 beats per minute, a blood pressure of $137 / 80 \mathrm{mmHg}$, oxygen saturation of $99 \%$ on room air, and a respiratory rate of 27 breaths per minute. He looked unwell and was worried about his epigastric pain; however, physical examination revealed normal peristaltic sounds and no abdominal tenderness and was otherwise unremarkable. Arterial blood gas tests on room air revealed a $\mathrm{pH}$ of 7.33, a $\mathrm{PCO}_{2}$ of $29.7 \mathrm{mmHg}$, bicarbonate of $15.3 \mathrm{mEq} / \mathrm{L}$, an anion gap of 27.5 $\mathrm{mEq} / \mathrm{L}$, lactate of $8.4 \mathrm{mmol} / \mathrm{L}$, and glucose of $45 \mathrm{mg} / \mathrm{dL}$ (Table 1). Other blood tests revealed aspartate aminotransferase of $129 \mathrm{U} / \mathrm{L}$, alanine aminotransferase of $49 \mathrm{U} / \mathrm{L}$, amylase of $73 \mathrm{U} / \mathrm{L}$, lipase of $12 \mathrm{U} / \mathrm{L}$, and hemoglobin A1c of 7.6\% (Table 2). The normal amylase and lipase levels were not suggestive of active pancreatitis. We did not measure his serum ketone levels. Dipstick urinalysis was positive for ketone bodies (Table 3). We did not measure his serum ethanol concentration because he and his wife separately denied his recent alcohol consumption. The urine drug test was also waived based on his current medical history. 


\section{Cureus}

\begin{tabular}{|l|l|l|l|l|}
\hline & $\begin{array}{l}\text { Reference } \\
\text { range }\end{array}$ & $\begin{array}{l}\text { On admission (Day 1, arterial } \\
\text { blood) }\end{array}$ & $\begin{array}{l}\text { Two hours later (Day 1, arterial } \\
\text { blood) }\end{array}$ & $\begin{array}{l}\text { Day 3 (venous } \\
\text { blood) }\end{array}$ \\
\hline $\mathrm{pH}$ & $7.35-7.45$ & 7.33 & 7.35 & 7.35 \\
$\mathrm{PCO}_{2}(\mathrm{mmHg})$ & $35-48$ & 29.7 & 22.1 & 47.6 \\
$\mathrm{PO}_{2}(\mathrm{mmHg})$ & $83-108$ & 103 & 107 & 35.1 \\
$\mathrm{HCO}_{3}-(\mathrm{mmol} / \mathrm{L})$ & $22.2-28.3$ & 15.3 & 12.1 & 25.7 \\
\hline $\begin{array}{l}\text { Glucose (mmol/L) } \\
\text { Lactate (mmol/L) }\end{array}$ & $3.6-5.3$ & 2.5 & 7.6 & 16.3 \\
\hline $\begin{array}{l}\text { Anion gap (mmol/L) } \\
\text { Base excess (mmol/L) }\end{array}$ & $-8-56-1.39$ & 8.4 & 11.4 & 3.6 \\
\hline $\begin{array}{l}\text { Plasma osmolality } \\
\text { (mOsm/L) }\end{array}$ & $-3.2-1.8$ & -9.4 & 26.0 & 10.6 \\
\hline
\end{tabular}

TABLE 1: Results of the blood gas tests. Blood samples were obtained from the artery on Day 1 and from the vein on Day 3.

\begin{tabular}{|c|c|c|c|c|c|c|c|}
\hline & Reference range & Day 1 & Day 2 & Day 3 & Day 6 & Day 10 & Day 13 \\
\hline White blood cell $(/ \mu \mathrm{L})$ & $4,000-9,000$ & 14,700 & 9,800 & 7,400 & 6,200 & 3,700 & 6,200 \\
\hline Hemoglobin (g/dL) & $14.0-18.0$ & 13.0 & 11.8 & 14.1 & 12.6 & 12.8 & 11.1 \\
\hline Platelet $\left(\times 10^{4} / \mu \mathrm{L}\right)$ & $15.0-35.0$ & 32.8 & 29.2 & 28.5 & 23.5 & 24.3 & 27.3 \\
\hline Total protein (g/dL) & 6.7-8.3 & 7.6 & & & & 6.9 & \\
\hline Albumin (g/dL) & $3.8-5.3$ & 4.6 & 4.4 & & 4.9 & 4.2 & 4.1 \\
\hline Aspartate aminotransferase (U/L) & 8-38 & 129 & 95 & 119 & 124 & 110 & 50 \\
\hline Alanine aminotransferase (U/L) & $4-44$ & 49 & 44 & 60 & 92 & 97 & 64 \\
\hline Lactate dehydrogenase (U/L) & 124-222 & 235 & 216 & 258 & 197 & 412 & 191 \\
\hline Y-glutamyl transferase (U/L) & $12-63$ & & & & 109 & 92 & 73 \\
\hline Sodium (mEq/L) & 135-147 & 140 & 133 & 135 & 139 & 137 & 141 \\
\hline Chlorine (mg/dL) & $98-108$ & 93 & 94 & 95 & 98 & 100 & 100 \\
\hline Potassium (mEq/L) & $3.6-5.0$ & 3.1 & 3.9 & 3.9 & 3.7 & 4.6 & 4.2 \\
\hline Urea nitrogen (mg/dL) & $8-20$ & 11.4 & 8.7 & 8.2 & 8.7 & 4.6 & 4.2 \\
\hline Creatinine (mg/dL) & $0.61-1.04$ & 0.64 & 0.57 & 0.60 & 0.63 & 0.59 & 0.73 \\
\hline Amylase (U/L) & $40-126$ & 73 & & & & & \\
\hline Lipase (U/L) & $13-42$ & 12 & & & & & \\
\hline Hemoglobin A1c (\%) & $4.6-6.2$ & 7.6 & & & & & \\
\hline C-reactive protein $(\mathrm{mg} / \mathrm{dL})$ & $0-0.2$ & 0.03 & 0.28 & 0.29 & 0.14 & $<0.03$ & $<0.03$ \\
\hline Prothrombin time (\%) & $80-120$ & 119 & 124 & & & & \\
\hline
\end{tabular}

TABLE 2: Laboratory data of the blood samples. 


\section{Cureus}

\begin{tabular}{|c|c|c|c|c|}
\hline & Reference range & Day 1 & Day 2 & Day 3 \\
\hline Urine specific gravity & $1.008-1.034$ & 1.021 & 1.017 & 1.018 \\
\hline pH & 4.8-7.5 & 5.5 & 6.5 & 6.5 \\
\hline Urine protein & - & \pm & \pm & - \\
\hline Urine sugar & - & $2+$ & - & $4+$ \\
\hline Urine ketone body & - & $3+$ & $1+$ & - \\
\hline
\end{tabular}

TABLE 3: Results of the dipstick urinalysis.

Two sets of blood cultures on admission were negative. Computed tomography scans of the abdomen with contrast revealed no remarkable changes, including signs suggestive of active inflammation of the remaining pancreas (Figure 1). Intravenous glucose and vitamin B1 supplementation was administered in the emergency department, and nutritional management for presumed starvation ketoacidosis was begun. His symptoms improved gradually, but his premeal blood glucose level hovered at more than $200 \mathrm{mg} / \mathrm{dL}$. A diagnosis of pancreatic diabetes was suspected based on decreased insulin secretion, normal insulin resistance, and negative anti-glutamic acid decarboxylase antibody (Table 4). Intensive insulin therapy was initiated, and he was discharged 15 days after admission. At his most recent visit, 30 days after discharge, he was asymptomatic and doing well.

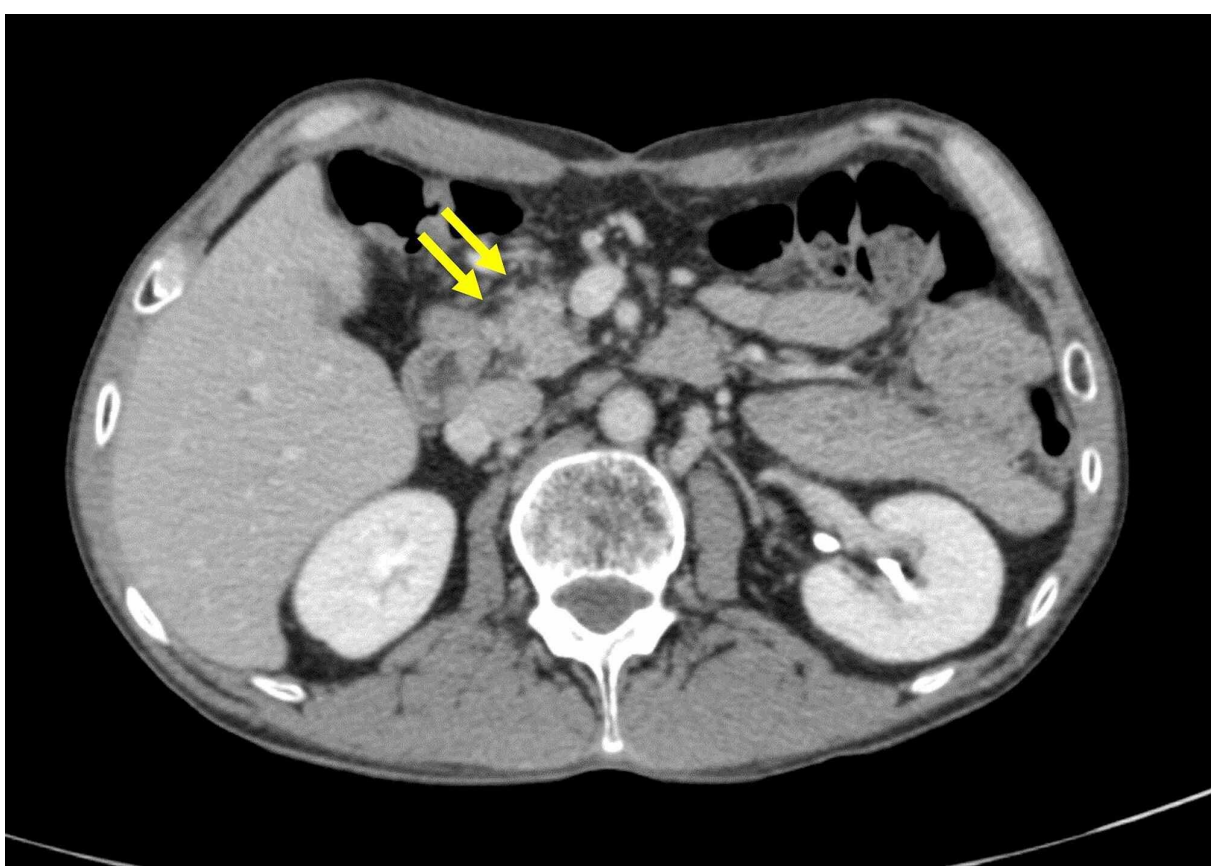

FIGURE 1: Computed tomographic scans of the abdomen with contrast. 


\section{Cureus}

\begin{tabular}{|c|c|c|c|}
\hline & Reference range & Day 7 & Day 10 \\
\hline Anti-GAD antibody (U/L) & $0-5$ & $<5$ & \\
\hline Preprandial serum C-peptide (ng/mL) & $0.69-2.45$ & 0.85 & 0.51 \\
\hline Postprandial two-hour serum C-peptide (ng/mL) & - & 2.74 & \\
\hline Preprandial serum insulin $(\mu \mathrm{U} / \mathrm{mL})$ & $1.1-17.0$ & 1.3 & 2.1 \\
\hline Postprandial serum insulin ( $\mu \mathrm{U} / \mathrm{mL})$ & - & 8.7 & \\
\hline Preprandial blood glucose $(\mathrm{mg} / \mathrm{dL})$ & $60-109$ & 152 & 123 \\
\hline Postprandial blood glucose (mg/dL) & - & 362 & \\
\hline
\end{tabular}

\section{TABLE 4: Laboratory tests to determine the type of diabetes mellitus.}

GAD, glutamic acid decarboxylase

\section{Discussion}

Here, we described a case of hypoglycemia and severe ketoacidosis in a patient with chronic pancreatitis. As his current history was not suggestive of alcoholic or drug-induced ketoacidosis, his ketoacidosis was thought to result from two days of fasting, and serum ethanol measurement and urine drug test were waived. Starvation ketosis usually presents with normal or mildly elevated blood glucose levels because of decreased renal glucose clearance and enhanced counterregulatory hormones such as adrenalin, cortisol, and growth hormones (Figure 2A) [5]; however, our patient presented with hypoglycemia. Hypoglycemia is usually caused by the inappropriate use of hypoglycemic drugs and insulin therapy in patients with diabetes. Other differential diagnoses include cortisol deficiency, growth hormone deficiency, insulinoma, sepsis, hepatic failure, renal failure, liver failure, and chronic alcohol use [6]; however, these conditions were not present in our case. Idiopathic ketonic hypoglycemia is known to cause hypoglycemia and ketonuria in children who are non-diabetic and typically occurs in those under five years of age [7]; however, this disorder rarely occurs in adults. The combination of hypoglycemia and ketonuria in our patient may be due to decreased alpha cell function resulting from chronic pancreatitis (Figure 2B). Although the proportion of alpha cells in the islets is only about 20-30\% [8], decreased alpha cells and glucagon secretion can result in a deteriorated defense mechanism against hypoglycemia. Additionally, decreased insulin secretion can cause a lack of glycogen storage in the liver and skeletal muscles [9]. This mechanism may also have contributed to hypoglycemia in our patient.

Our case is also notable for metabolic ketoacidosis with significantly decreased serum bicarbonate, which is uncommon among patients with starvation ketosis. In patients with starvation ketosis, the degree of acidosis is relatively mild, with the serum bicarbonate concentration not lower than $18 \mathrm{mEq} / \mathrm{L}$ (Figure 2A) [4]. This may be because insulin secretion in such patients is usually sufficiently maintained so as not to promote excessive ketogenesis [10]. In our patient, the combination of chronic pancreatitis and starvation seemed to have resulted in strong insulin secretion suppression and subsequent excessive ketogenesis, as seen in diabetic ketoacidosis (DKA) (Figure $2 B$ ). Recently, the concept of euglycemic DKA with a blood glucose level of less than $200 \mathrm{mg} / \mathrm{dL}$ has been proposed [4], with which the characteristics of our case seem to overlap.

(A)

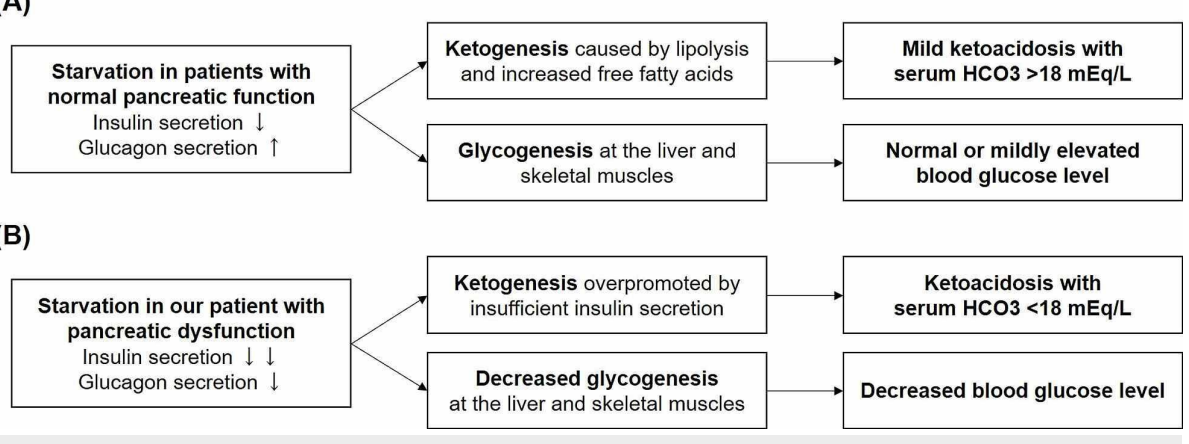

FIGURE 2: Pathophysiology of starvation ketosis. (A) In patients with normal pancreatic function, maintained insulin secretion usually prevents excessive ketogenesis, which results in relatively mild 


\section{Conclusions}

Short-term fasting can cause hypoglycemia in patients with decreased pancreatic function. It can also cause metabolic acidosis with significantly decreased serum bicarbonate, leading to severe illness and hospitalization. Starvation ketosis in our patient seemed to resemble DKA; thus, further reports should be accumulated to determine whether starvation ketosis accompanied by pancreatic dysfunction and DKA form an overlapping syndrome.

\section{Additional Information}

\section{Disclosures}

Human subjects: Consent was obtained or waived by all participants in this study. Conflicts of interest: In compliance with the ICMJE uniform disclosure form, all authors declare the following: Payment/services info: All authors have declared that no financial support was received from any organization for the submitted work. Financial relationships: All authors have declared that they have no financial relationships at present or within the previous three years with any organizations that might have an interest in the submitted work. Other relationships: All authors have declared that there are no other relationships or activities that could appear to have influenced the submitted work.

\section{Acknowledgements}

We are grateful to Dr. Thomas D. Mayers, Medical English Communications Center, University of Tsukuba, for the grammatical revision of this manuscript. We are also grateful to Dr. Yasuhiro Ogawa, Division of Hospital Medicine, University of Tsukuba Hospital, for daily clinical practices.

\section{References}

1. Beyer G, Habtezion A, Werner J, Lerch MM, Mayerle J: Chronic pancreatitis. Lancet. 2020, 396:499-512. 10.1016/S0140-6736(20)31318-0

2. Holst JJ, Holland W, Gromada J, et al.: Insulin and glucagon: partners for life . Endocrinology. 2017, 158:696701. 10.1210/en.2016-1748

3. Sinha N, Venkatram S, Diaz-Fuentes G: Starvation ketoacidosis: a cause of severe anion gap metabolic acidosis in pregnancy. Case Rep Crit Care. 2014, 2014:906283. 10.1155/2014/906283

4. Barski L, Eshkoli T, Brandstaetter E, Jotkowitz A: Euglycemic diabetic ketoacidosis. Eur J Intern Med. 2019, 63:9-14. 10.1016/j.ejim.2019.03.014

5. Burge MR, Garcia N, Qualls CR, Schade DS: Differential effects of fasting and dehydration in the pathogenesis of diabetic ketoacidosis. Metabolism. 2001, 50:171-177. 10.1053/meta.2001.20194

6. Kitabchi AE, Umpierrez GE, Murphy MB, Barrett EJ, Kreisberg RA, Malone JI, Wall BM: Management of hyperglycemic crises in patients with diabetes. Diabetes Care. 2001, 24:131-153. 10.2337/diacare.24.1.131

7. Daly LP, Osterhoudt KC, Weinzimer SA: Presenting features of idiopathic ketotic hypoglycemia . J Emerg Med. 2003, 25:39-43. 10.1016/s0736-4679(03)00100-8

8. Arrojo e Drigo R, Ali Y, Diez J, Srinivasan DK, Berggren PO, Boehm BO: New insights into the architecture of the islet of Langerhans: a focused cross-species assessment. Diabetologia. 2015, 58:2218-2228. 10.1007/s00125-015-3699-0

9. Cohen P, Nimmo HG, Proud CG: How does insulin stimulate glycogen synthesis?. Biochem Soc Symp. 1978, 43:69-95.

10. Palmiere C, Tettamanti C, Augsburger M, Burkhardt S, Sabatasso S, Lardi C, Werner D: Postmortem biochemistry in suspected starvation-induced ketoacidosis. J Forensic Leg Med. 2016, 42:51-55. 10.1016/j.jflm.2016.04.013 